\title{
Secondary stress in morphologically complex words in Faroese: A word game*
}

Nicole Dehé and Allison Wetterlin

\section{Introduction: Word stress in Faroese}

Word stress, and in particular the distribution of secondary stress in Insular Scandinavian has yet to be systematically studied and the phonetic correlates in production and perception have yet to be identified (this was noted for Icelandic by Zonneveld et al. 1999: 570 and new studies have not been added since then). The present paper reports on a pilot study that was designed to systematically ascertain the correlates of word stress in Icelandic and Faroese, starting out with Faroese.

In the literature, we find the basic Faroese word stress rules summarised as in (1) (see Thráinsson et al. 2004: 28).

(1) Basic word stress rules in Faroese

a. Primary stress falls on the first syllable in all native Faroese words.

b. There is a stress alternation rule which places a weak secondary stress on every other syllable.

c. The first syllable of the second part of compound words gets secondary stress.

According to these rules, word stress in Faroese is very similar to that of its close relative Icelandic. First of all, like Icelandic, Faroese has retained the typical Germanic word stress pattern such that (the majority of) native words have primary stress on the initial syllable of a word (cf. also Lockwood 1977: 8, Barnes and Weyhe 1994: 196, Árnason 2011: 275 and references given there). Secondly, according to (1)b, Faroese also has alternating secondary stress, as illustrated below in (2)a (see also Árnason 1985 and 2011). Secondary stress is said to be rhythmically motivated in both languages. It follows a strengthening rule (Árnason 1985 for Icelandic), which creates alternating stress starting from the primary stress on the first syllable (see (3)a-c). This rhythmic rule has the consequence that second ary stress can also fall on inflectional suffixes. For example, Icelandic 'ung\#barn, io in (3)b has secondary stress on the suffixed definite article $-i \delta$, while barn 'child' is weakened. This is not a trait found in the other Germanic languages, and in the context of Icelandic the

\footnotetext{
This research was made possible by an AFF grant from the University of Konstanz. We would like to express our thanks to the Faculty of Faroese at the University of the Faroe Islands for their support and the use of their facilities. Special thanks go to Gurrio Poulsen and all the participants for their interest and endurance.
} 
assumption has not remained undisputed (see Gussmann 1985, Hayes 1995). However, it appears as if Faroese also has alternating secondary stress which can fall on suffixed definite articles as observed by Árnason (2011); see his examples in (4).'

(2) Word stress in Faroese ${ }^{2}$

\begin{tabular}{|c|c|c|c|}
\hline & STRESS PATTEERN & EXAMPLE: & GLOSS \\
\hline a. & $' \sigma \sigma \#, \sigma \sigma$ & $\begin{array}{l}\text { 'grindałt,hvalur } \\
\text { 'ongat,staðni }\end{array}$ & $\begin{array}{l}\text { 'pilot whale' } \\
\text { (no\#tplace) 'nowhere' }\end{array}$ \\
\hline b. & ' $\sigma \neq ⿰ 木, \sigma$ & 'Ís\#,land & 'Iceland' \\
\hline c. & ' $\sigma \#, \sigma \sigma$ & $\begin{array}{l}\text { 'isł",lendskur } \\
\text { 'til\#,biðja }\end{array}$ & $\begin{array}{l}\text { 'Icelandic' } \\
\text { (tołpray) 'worship' }\end{array}$ \\
\hline d. & ' $\sigma \sigma \sigma \#, \sigma \sigma$ & 'kjallaratt,búgvi & 'cellar dweller' \\
\hline
\end{tabular}

(3) Word stress in Icelandic

\begin{tabular}{|c|c|c|c|}
\hline & STRESS PATTERN & EXAMPLE & GLOSS \\
\hline $\mathrm{a}$ & $\sigma \sigma \#, \sigma \sigma$ & 'ferða\#,maður & vel-GEN.PLHman) 'tourist' \\
\hline & ' $\sigma$ \# $\sigma, \sigma$ & 'ung\#barn,ið & (young\#child ${ }_{\mathrm{DFF}}$ 'infant, baby' \\
\hline c. & ' $\sigma \# \sigma, \sigma$ & 'boröpla,ta & (table\#plate) 'table top' \\
\hline d. & ' $\sigma \sigma \sigma \#, \sigma \sigma$ & 'kartöflü, flögur & (potato\#flakes) 'potato crisps' \\
\hline
\end{tabular}

(4) Alternating stress in Faroese: secondary stress on the suffixed definite article (examples from Árnason 2011: 96, 276)

\begin{tabular}{llll} 
& STRESS PATTERN & EXAMPLE & GLOSS \\
\hline a. ' $\sigma \sigma, \sigma$ & 'báti,num & 'boat.the \\
b. ' $\sigma \sigma, \sigma \mathrm{T}$ & ' \\
c. ' $\sigma \sigma ; \sigma$ & 'húsi,num & 'house.the ${ }_{\mathrm{DAT}}$ ',
\end{tabular}

In Icelandic, the rhythmic rule wins over morphological structure such that in compounds with monosyllabic first components, the secondary stress is on the second syllable of the second morphological component (instead of initial stress in the second component; see (3)c). Faroese differs from Icelandic in this respect. In compounds or otherwise morphologically complex words with monosyllabic first components, Faroese follows the compound stress rule in (1)c. As Thráinsson et al. (2004: 28) explain, the compound rule wins out over the alternating stress rule, creating words with primary and secondary stress on adjacent syllables (see (2)b, c).

One exception to alternating stress in both Faroese and Icelandic is given in (2)d and (3)d, respectively, where due to the morphological structure (a trisyllabic first component), two unstressed syllables intervene between primary and secondary' stress, following the compound stress rule in (1)c.

1 Throughout the paper, the following symbols are used: single superscripted (') or subscripted () vertical lines preceding the syllable indicate main (primary) and secondary stress, respectively. A sigma $\sigma$ denotes a syllable and a hash mark \# indicates a boundary between the components of morphological compounds, = indicates a functional morpheme boundary (inflection).

2 The examples are taken from Thráinsson et al. (2004: 28) and Lockwood (1977: 8). 
Another important difference between Icelandic and Faroese is that it is much more common for words to have non-initial primary stress in Faroese than in Icelandic; see, for example, Lockwood (1977: 8), Barnes and Weyhe (1994: 196), Zonneveld et al. (1999; 583). This is true for loanwords (see (5)) as well as native Faroese words, e.g., compound adverbs (see (6)).

Another relevant property of Faroese is that "certain forms may vacillate between right" strong and left-strong patterns" (Zonneveld et al. 1999: 583), for example, a compound such as burdar\#vektir 'birth\#weight' may be realised either as burdar,vektir or , burdar vektir.

(5) Non-initial primary stress in non-native Faroese words;

examples from Barnes and Weyhe (1994: 196), Árnason (2011:278)
a. stu'dentur 'student'
b. ameri'kanari 'an American'
c. poli'ti 'police'

(6) Non-initial primary stress in native Faroese words;

examples from Zonneveld et al. (1999: 583), Árnason (2011: 277)
a. harum' framt 'furthermore'; lit: 'here-about\#further'
b. ser'stakliga 'specially'; lit: 'each\#individually'
c. aftu'rum 'behind'; lit: 'after\#about'

Relatively little is known about the phonetic cues to word stress in Faroese and in particular to the cues for secondary stress. Across languages most of the relevant literature on stress focusses more on the difference between stressed and unstressed syllables than on the difference between primary and secondary stress (see the recent discussion in Plag, Kunter and Schramm 2011). Generally speaking, phonetic cues to stress found for various languages include syllable and segment duration, vowel quality, pitch movement, and intensity. For German, Kleber and Klipphahn (2006) did not find any phonetic evidence for rhythmical secondary stress in their study, which compared the acoustic correlates of vowel duration, intensity, and F0 among others for syllables with primary stress, secondary stress, and no stress. However, some experimental evidence has been provided specifically for phonetic cues to secondary stress in other languages. For example, pitch movement and amplitude peak have been identified as cues to word-initial secondary stress in Spanish (Prieto and van Santen 1996).

More specifically for Insular Scandinavian, durational and F0 cues are likely to be candidates for signalling stress. In particular, the syllabic nucleus is described as being lengthened under stress in Icelandic (e.g., Haugen 1958, Zonneveld et al. 1999: 568) and Faroese (Árnason 2011), i.e., lengthening of the vowel in open syllables, and the final consonant in closed syllables with non-extrametrical final consonants. Unlike the syllable nucleus, the role of the syllable onset is not prominent in the literature, thus nothing is known about whether there is also lengthening of the syllable onset under stress.

In Icelandic, aspiration of intervocalic stops may also be a possible indicator of (secondary) stress. The two main varieties of Icelandic behave differently in this respect. The "hard" (northern) variety has aspirated stops between vowels in non-stress positions, e.g., in words like taka (['tha:. $\left.\mathrm{k}^{(\mathrm{h})} \mathrm{a}\right]$ 'to take') and batur (['pau.t(h)Yr] 'boat'). On the other hand, aspiration of stops in the "soft" (southern) varieties of Icelandic indicates foot-initial posi- 
tion, thus stress position; in this variety, stops in the onset of unstressed syllables are unaspirated (Thráinsson and Ámason 1992, Árnason 2011). Similarly, according to Árnason (2011), northern varieties of Faroese tend to have aspiration (postaspiration or preaspiration) in word internal position (and then only after non-high vowels), whereas southern varieties have unaspirated medial stops. However, according to Árnason (2011: 119-20), there is "quite a bit of variation" regarding soft/hard dialects and aspiration in Faroese "and the picture is not entirely clear". The soft/hard distinction "as far as it applies to internal onsets, is only based on preaspiration. Thus aspiration in internal onsets is only marginal in Faroese" (see also Thráinsson et al. 2004). However, this has never been tested systematically.

Furthermore, reduction/deletion processes common in both Icelandic and Faroese are sensitive to the difference between unstressed syllables and syllables with some degree of stress such that they may apply to the former but not the latter (e.g., Zonneveld et al. 1999: 570, Árnason 2011:276). ${ }^{3}$

Another cue to secondary stress in Icelandic mentioned in the literature is pitch movement. Zonneveld et al. (1999: 570) maintain that syllables with secondary stress can attract pitch accents; pitch movement would be associated with the relevant syllable. This is related to a claim made by Dehé (2009) that syllables with secondary stress can be associated with phrase accents, i.e., a tonal target after the last pitch accent in an intermediate phrase.

The aims of the study reported on here are as follows: (i) to ascertain the location of secondary stress in production and perception, (ii) to identify the most prominent phonetic parameters related to secondary stress in production and perception, and (iii) to compare secondary stress on lexical and functional morphemes.

\section{The experiment}

In order to approach the research questions outlined above in a way that would enable us to ultimately compare Icelandic and Faroese data, a pilot word game was designed in which words were conveyed by one participant to another only by using the syllables ta ta ta or na na na. Production data were elicited to investigate the phonetic cues indicating stress, and perception was relevant under the assumption that if a word is produced and subsequently recognised, the phonetic cues employed by the speaker conveyed the stress pattern successfully. The sequences ta ta ta and na na na were used in order to control the segmental environment. More specifically, they were chosen for the following reasons: in ta ta ta, the segmental make-up was ideal to test closure duration (onset plosive), voice onset time

3 However, note that in Icelandic, syllables which would be predicted to have rhythmically deter. mined secondary stress at word level may be lost at sentence level due to Final Vowel Deletion (FVD), a rule which deletes a word-final vowel before an initial vowel on the following word. For example, in (x) below, the final syllable of barninu would carry secondary stress according to (1)b, but can be deleted in the given context. (See Dehé 2008 for details.)

(x) Maríagaf barninu epli.

Mariagave child the apple 
(VOT)/aspiration and vowel duration; in na na na, the segmental make-up was ideal to test vowel duration, onset consonant duration, and, due to continuous voicing, pitch movement.

\subsection{Stimuli design and methods}

Eighty-eight morphologically complex Faroese words were found, considering different morphological and rhythmic patterns. Twenty-two functioned as target words and 66 were distracters. The target words fall into the groups exemplified in Table 1. Word group (a) consists of compounds with mono-syllabic first components; primary stress is on the first syllable, secondary stress is predicted to be on the second syllable according to the compound rule given above in (1)c. Groups $(b-g)$ consist of morphologically complex words with disyllabic first components. In this group, primary stress is on the word-initial syllable, and secondary stress is on the first syllable of the second morphological component; however, if the second component does not follow the native stress-initial pattern, secondary stress may be elsewhere (see ( $\mathrm{f}$ ) in Table 1). The word bikarid in group (d) only has an inflectional morphological boundary separating the second and third syllable. In group (h), the first lexical component of each word consisted of three syllables, the first one bearing primary stress; secondary stress was on the fourth syllable, i.e., the first syllable of the second component according to (l)c. Groups (i-k) had non-initial primary stress with varying positions of both primary and secondary stress. The predictions with regard to stress positions will be explained in more detail below.

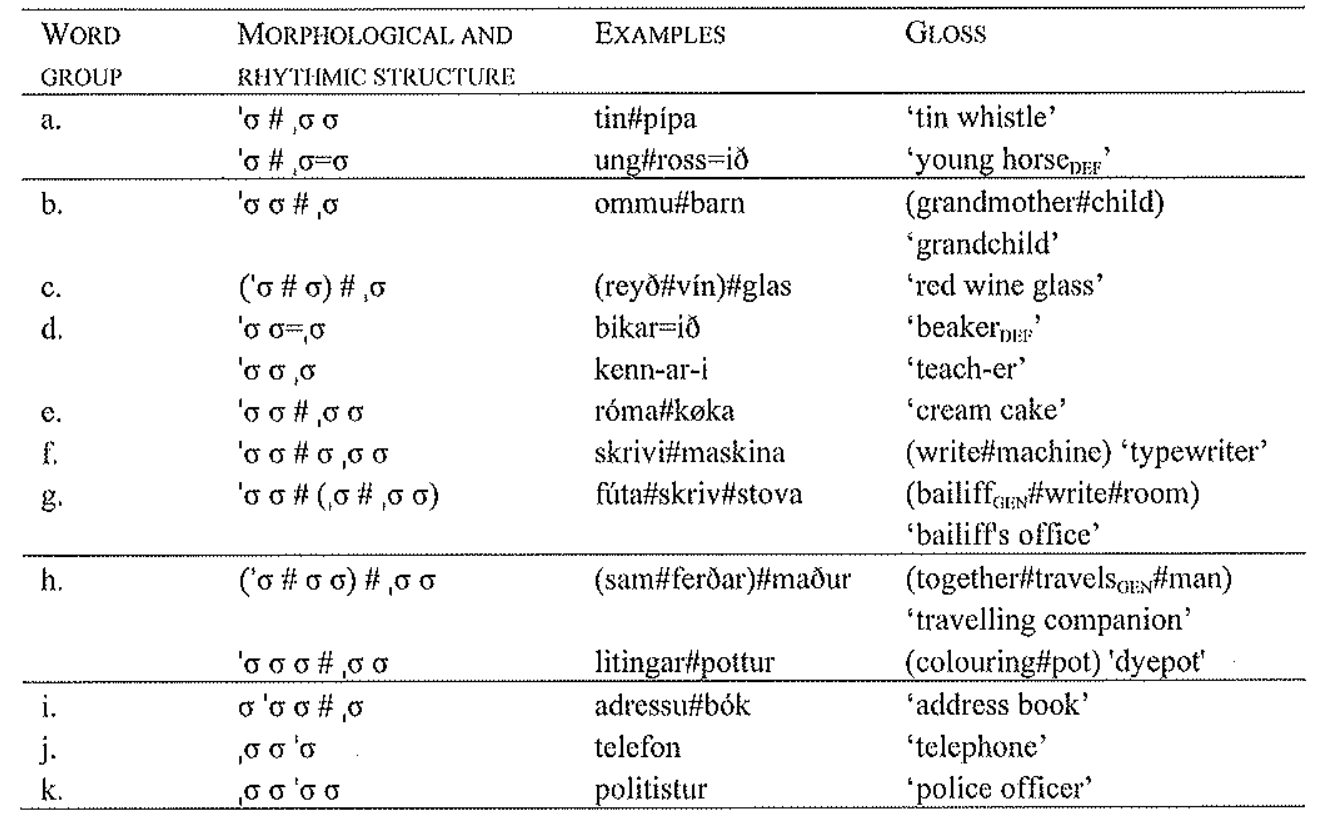

Table 1: Example words illustrating morphological and rhythmical patterns 


\subsection{Participants}

The experiment was carried out with 34 participants (17 pairs) in July 2011 by the authors in three locations on the Faroe Islands. The participants were between 19 and 60 years of age; they were four male and 30 female native speakers of Faroese. Sixteen participants (8 pairs) were tested in Tórshavn (Streymoy Island) at the University of the Faroe Islands, sixteen (8 pairs) at a local school in Miðvagi (Vágur Island), and two participants (one pair) at a private home in Vágur (Suðuroy Island).

\subsection{Procedure}

Two participants (A and B) were each seated in front of a computer screen, that could not be seen by the other participant (see left-hand panel of Figure 1). The participants received written and oral instructions in Faroese as to the procedure of the game. The game commenced as one word appeared on participant A's screen and a list of four words (in pseudorandomised order) appeared on participants B's screen (see right-hand panel of Figure 1). These four words included the target word, i.e., the word on participant A's screen (skrivimaskina ' $\sigma \sigma \# \sigma, \sigma \sigma$ in Figure 1), and three other words. These three words differed from the target in length (one syllable too few or too many; not more than one distracter per trial; bókamessa ' $\sigma \sigma \#, \sigma \sigma$ in Figure 1), and/or rhythmical pattern (position of primary or secondary stress; at least two distracters per trial; ónoktiligur and sømdarpeningur, both ' $\sigma \sigma$ \# $, \sigma \sigma, \sigma$, in Figure 1). None of the three distracters had the same morphological or thythmic structure as the target. Participant A was instructed to convey the word on the screen to B solely using the syllables tatata in such a way that $B$ would be able to guess which word it was. Participant $\mathrm{A}$ was not allowed to say the actual word at any time, but was only allowed to say ta ta ta or later na na na using as many ta $a \mathrm{~s}$ or na-s as needed. Each ta corresponded to one syllable of the target word. After hearing the tatata-sequence, Participant B tried to figure out which word it was, then asked $A$ to repeat the word, this time using nanana. After hearing the nanana variation, participant $\mathrm{B}$ considered the words in the list again and made a guess. The participants moved on to the next trial when the word was correctly identified. Three guesses were allowed. If $B$ did not recognise the word, participant $A$ revealed the target word and then moved on to the next word. The participants changed roles at half time, i.e., after 11 words. 


\begin{tabular}{ll}
\hline TWO PARTICIPANTS & COMPUTER SCRELNS: \\
PLAYING THE WORD GAME: & DEPICTING WITAT EACH PARTICTPANT SEES \\
\hline
\end{tabular}

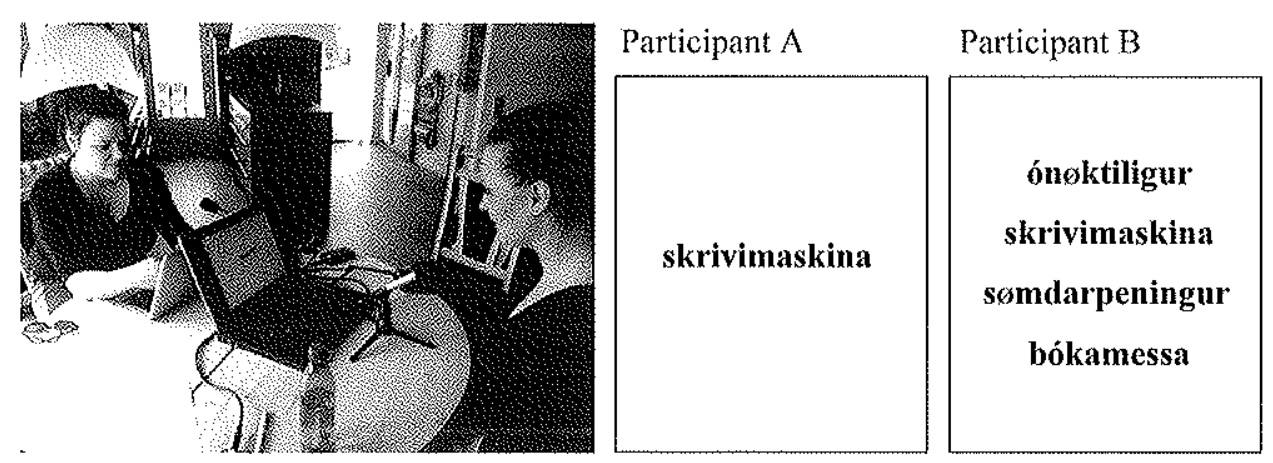

Figure 1: Word game; left-hand panel: two participants playing the word game; right-hand panel: computer screens for one trial as seen by participant A on the left and participant B on the right (glosses: ónoktiligur 'who never gets enough; impossible to satisfy'; skrivimaskina 'typewriter'; 'sømdarpeningur 'honorary pension'; bókamessa 'book fair')

\subsection{Recordings}

All word game sessions were recorded using two Microtrack II (M-Audio) recorders and two Rode NT-5 condenser microphones. All recordings were then edited into individual sound files and analysed in Praat (Boersma and Weenink 2012).

\subsection{Analysis}

A minimum of 22 tatatas and nananas ( 2 speakers, 11 words each) were extracted per pair, plus repetitions. The tatata- and nanana-sequences were annotated for the following landmarks, as illustrated in Figures 2 and 3; tatata: closure duration (cd), voice onset time (vot), and vowel duration (v) for each syllable $(\sigma)$; note that the beginning of the very first cd was set arbitrarily because closure duration cannot be identified at the beginning of an utterance; nanana: consonant (c) and vowel (v) duration for each syllable $(\sigma)$. In Figures 2 and 3 , the numbers indicate the number of the syllable, e.g., $\mathrm{v} 4$ is the duration of the vowel in the fourth syllable. 


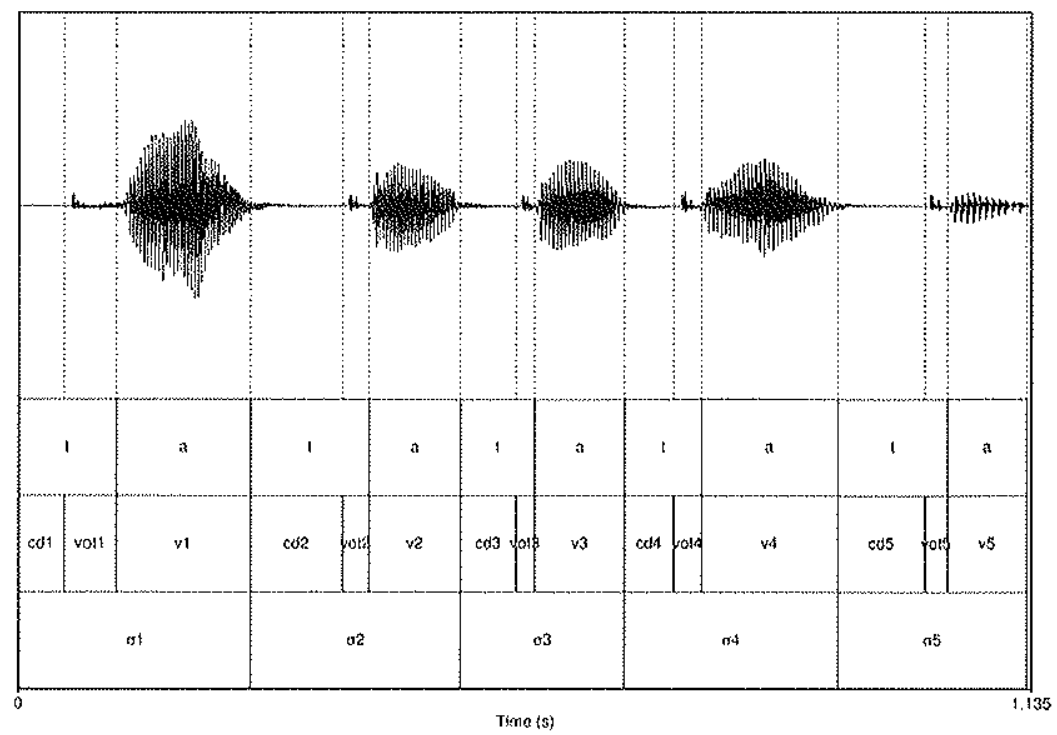

Figure 2: Annotated sound file of a tatata sequence (Speaker M14) conveying skrivimaskina ('type writer')

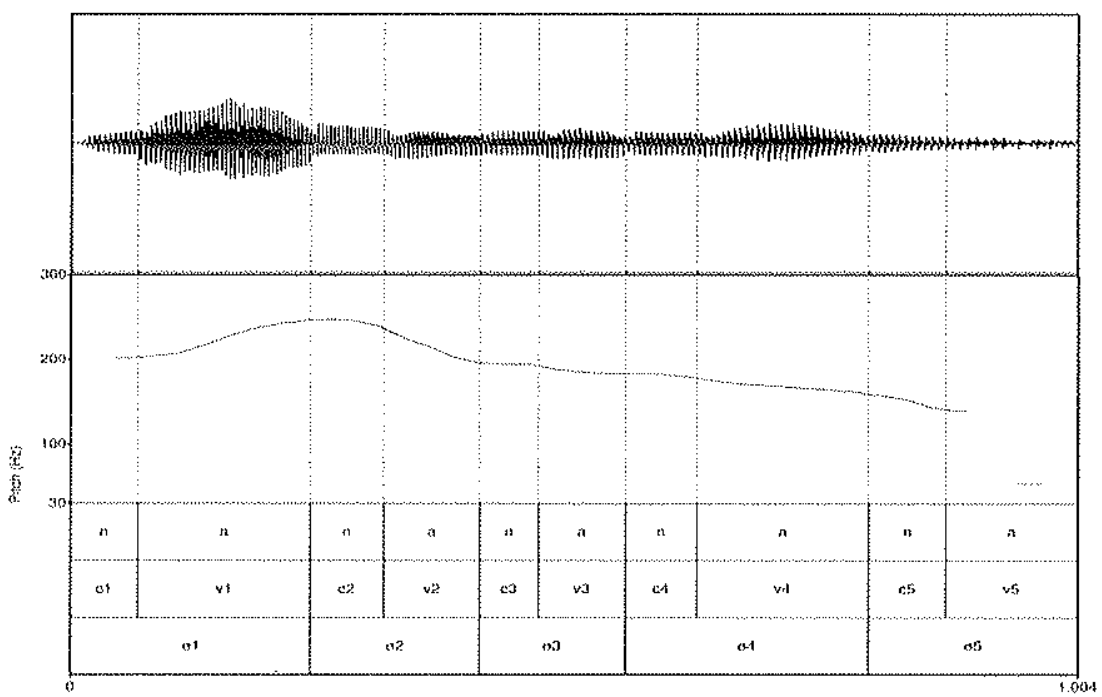

Figure 3: Annotated sound file of a nanana sequence (Speaker M14) conveying skrivimaskina ('type writer') 


\subsection{Results and discussion}

As is well known amongst phonology and phonetics lecturers, not all students are readily able to hear and correctly convey word stress even if they make intuitive use of it in both production and perception of their native language. Therefore we were anticipating that some pairs would not work out well in the word game. Since we were to find out how stress is produced as well as the acoustic correlates that are important to identify stress, we only included words in the analysis that were correctly identified. Moreover, we only took correctly identified words from participants who were able to correctly identify more than $64 \%$ of the test words. The main results are reported on in this section.

The results are given in milliseconds and are grouped according to number of syllables for easier comparison and listed according to average VOT (Tables 2 and 6) and vowel duration (V) (Tables 3 and 7) for the ta ta ta tokens, and according to vowel duration (V) (Tables 4 and 8) and consonant duration (C) (Tables 5 and 9) for the na na na tokens. The word groups $(\mathrm{a}-\mathrm{k})$ in Tables 2 through 9 are identical to those in Table 1 above. We begin with the results for a set of trisyllabic words with varying morphological structures (Tables 2 through 5 organised according to morphological patterns and phonetic parameters). Recall that if secondary stress is rhythmically motivated (compare (1)b and the Icelandic pattern), then secondary stress should be placed on the third syllable across the board, i.e., for all words regardless of the morphological structure. If, on the other hand, secondary stress follows the compound rule in (1)c, then it should be realised on the second syllable in the words of group (a) in Tables 2 through 5, but on the third syllable in the tokens for group (b). Group (c) consists of a morphologically complex first constituent reyð\#tvin 'red wine' and glas 'glass', thus both rhythmically and morphologically motivated secondary stress would be expected on the third syllable. However, according to the compound rule in (1)c, a secondary stress might also occur on the second syllable. In group (d), the word bikarid differs from kennari morphologically in that it includes the suffixed definite article $-i \delta$, while kennari is a derivative with the masculine agentive suffix $-a r-i$ 'teach-er'. However, this made no difference in any of the measurements, thus their results are grouped together. Rhythmically, if Faroese is similar to what is reported for Icelandic, secondary stress should be on the third syllables in these examples, i.e. on the suffixed definite article in bikarid. ${ }^{4}$

4 In the tables below, shaded cells indicate values which correspond to positions of secondary stress as predicted according to (1); in case of conflict between (1)b and ( $) c$, predictions are according to the compound rule in $(1) \mathrm{c}$. 


\begin{tabular}{|c|c|c|c|c|c|c|}
\hline & WORD GROUP & EXAMPLES & TOKENS & $\begin{array}{l}\text { AVERAGE } \\
\text { VOT } \sigma !\end{array}$ & $\begin{array}{l}\text { AVERAGE } \\
\text { VOT } \sigma 2\end{array}$ & $\begin{array}{l}\text { AVERAGE } \\
\text { VOT } \& 3\end{array}$ \\
\hline a. & ' $\sigma \#, \sigma \sigma$ & tinpípa & 12 & 63.4 & 42 & 37.1 \\
\hline b. & $' \sigma \sigma \#, \sigma$ & ommubarn & 8 & 55.5 & 34.8 & 40.2 \\
\hline c. & $' \sigma-\sigma \#, \sigma$ & reyouvinglas & 4 & 68.5 & 37.7 & 52.1 \\
\hline d. & $\begin{array}{l}\text { ' } \sigma \sigma={ }_{t} \sigma \\
' \sigma \sigma, \sigma\end{array}$ & $\begin{array}{l}\text { bikariò } \\
\text { kennari }\end{array}$ & 12 & 51.6 & 37.2 & 37.8 \\
\hline
\end{tabular}

Table 2: Average voice onset time (VOT) of syllable onset /t/ in msec; ta ta ta: 3 syllable words

\begin{tabular}{|c|c|c|c|c|c|c|}
\hline & WORD GROUP & EXAMPLES & TOKENS & $\begin{array}{l}\text { AVERAGE } \\
V \sigma 1\end{array}$ & $\begin{array}{l}\text { AVERAGE } \\
\mathrm{V} \circ 2\end{array}$ & $\begin{array}{l}\text { AVERAGE } \\
V \sigma 3\end{array}$ \\
\hline a. & ${ }^{\prime} \sigma \#, \sigma \sigma$ & tinpipa & 12 & 214.8 & 121.5 & 114 \\
\hline b. & ${ }^{\prime} \sigma \sigma \# \sigma$ & ommubarn & 8 & 137.2 & 106.7 & 160 \\
\hline$c$ & ${ }^{\prime} \sigma-\sigma \#, \sigma$ & reyơvínglas & 4 & 195.8 & 135.1 & 134.7 \\
\hline d. & $\begin{array}{l}{ }^{1} \sigma \sigma=, \sigma \\
{ }^{1} \sigma \sigma, \sigma\end{array}$ & $\begin{array}{l}\text { bikariò } \\
\text { kennari }\end{array}$ & 12 & 156.1 & 127.8 & 115.5 \\
\hline
\end{tabular}

Table 3: Average vowel duration (V) in msec; ta ta ta: 3 syllable words

\begin{tabular}{|c|c|c|c|c|c|c|}
\hline & WORD GROUP & EXAMPLES & T'OKENS & $\begin{array}{l}\text { AVERAGE } \\
\text { V } \sigma l\end{array}$ & $\begin{array}{l}\text { AVERAGE } \\
\text { V } \sigma 2\end{array}$ & $\begin{array}{l}\text { AVERAGE } \\
\text { V } \sigma 3\end{array}$ \\
\hline a. & ${ }^{\prime} \sigma \#, \sigma \sigma$ & tinpípa & 12 & 253.5 & 136 & 126.8 \\
\hline b. & $\sigma \sigma \#, \sigma$ & ommubarn & 8 & 122.4 & 105 & 127 \\
\hline c. & $' \sigma-\sigma \#, \sigma$ & reyovínglas & 4 & 270 & 179.6 & 116.3 \\
\hline d. & $\begin{array}{l}' \sigma \sigma=, \sigma \\
\prime \sigma \sigma, \sigma\end{array}$ & $\begin{array}{l}\text { bikarið } \\
\text { kennari }\end{array}$ & 12 & 226.5 & 113.4 & 114.9 \\
\hline
\end{tabular}

Table 4: Average vowel duration (V) in msec; na na na: 3 syllable words

\begin{tabular}{|c|c|c|c|c|c|c|}
\hline & WORD GROUP & EXAMPLES & TOKENS & $\begin{array}{l}\text { AVERAGE } \\
\text { Col }\end{array}$ & $\begin{array}{l}\text { AVERAGE } \\
\mathrm{C} \sigma 2\end{array}$ & $\begin{array}{l}\text { AVERAGE } \\
\mathrm{C} \sigma 3\end{array}$ \\
\hline a. & ' $\sigma \#, \sigma \sigma$ & tinpípa & 8 & 97.1 & 112.6 & 81.3 \\
\hline b. & $\omega \sigma \#, \sigma$ & ommubarn & 8 & 56.5 & 82 & 77.6 \\
\hline c. & ${ }^{\prime} \sigma-\sigma \#, \sigma$ & reyơvínglas & 4 & 117 & 89.5 & 115.2 \\
\hline d. & $\begin{array}{l}{ }^{\prime} \sigma \sigma=, \sigma \\
\alpha \sigma \sigma, \sigma\end{array}$ & $\begin{array}{l}\text { bikarið } \\
\text { kennari }\end{array}$ & 12 & 54.4 & 58 & 91.8 \\
\hline
\end{tabular}

Table 5: Average consonant duration (C) in msec; na na na: 3 syllable words 
VOT (Table 2)

The average duration of the VOT of the onset consonants on each syllable of the trisyllabic tatata words in Table 2 correlates with the morphological structure. In groups (a-c) the VOT for the onset of the syllables following the morpheme boundary is greater than that of the unstressed syllable. This is our first hint at secondary stress and it is true regardless of whether primary and secondary stress are on adjacent syllables (group a) or not (groups b and c). When no lexical morpheme boundary is present (group d), the VOT of the onset of the second and third syllable do not differ, thus giving us our first indications that there is no rhythmical stress on the third syllable (e.g., the suffixed definite article) of these words.

\section{Vowel duration (Tables 3 and 4)}

The average vowel durations for the tatata and nanana tokens reported in Tables 3 and 4, respectively, behave similarly. We find that vowels are longer in syllables directly following a morphological boundary than in unstressed syllables in groups (a) and (b). However, it should be noted that in group (b) the duration of the vowel following the morphological boundary in words such as ommu\#barn is even longer than that of the stressed syllable. This may be a case of a vacillating stress pattern. In group (c) ([reyð\#vín]\#glas), vowel duration does not differentiate between the second and third syllables in the tatata tokens - it is only significantly longer in the syllable bearing main stress. This reflects the conflict noted above: the morphological rule predicts secondary stress both on the second and third syllable due to the complex morphological structure, while the rhythmical rule only suggests secondary stress on the third syllable. The same result was found for the nanana tokens of the category without a lexical morpheme boundary in (d). For the nanana tokens of [reyð\#vin]\#glas as well as for the tatata tokens of group (d) vowel duration decreases with distance to the main stressed syllable where it is the longest for the first syllable, again giving us no indication of rhythmical secondary stress on the third syllable.

\section{Consonant duration (Table 5)}

The average consonant durations for the nananas show the least amount of correspondence to morpheme boundaries. In groups (a) and (c) consonants of the main stressed syllable and after a morpheme boundary are the longest. For group (b), the syllable not predicted to bear stress either because of a morpheme boundary or because of word rhythm has the longest consonant. In group (d), consonant duration is greatest in the word final syllable, which would correspond to rhythmical stress on every other syllable. However, since this finding does not comply with the findings for VOT and vowel duration, which otherwise seem to be more reliable correspondents of stress positions, we will not interpret consonant duration here as a cue to secondary stress on the third syllable.

The next set of results we report on is for compounds of four or five syllables length with disyllabic and trisyllabic first constituents (groups $\mathrm{e}-\mathrm{h}$ in Tables $6-9$ below), as well as words with non-initial primary stress (groups $\mathrm{i}-\mathrm{k}$ in Tables $6-9$ ). The tables again summarise the mean durational values. For compounds with disyllabic first components and initial primary stress in both components (groups $\mathrm{e}$ and $\mathrm{g}$ ) the compound rule and alternating stress 
rule make identical predictions. Secondary stress should be realized on the first syllable of the second component, i.e. on the third syllable. In group $(\mathrm{g})$, an additional secondary stress should either fall on the fifth syllable according to the stress alternation rule in (1)b, or, indicated here, on the fourth syllable according to the compound rule in (1)c. In group (f), a secondary stress is predicted on the fourth syllable due to non-initial primary stress in the second component. In compounds with trisyllabic first components and native stress pattern (group h), the secondary stress should follow the compound rule in (1)c and fall on the fourth syllable of the compound winning over the alternating stress rule. The stress patterns of the words in groups (i-k) follow their morphological make-up such that adressubók is predicted to have secondary stress on the fourth syllable bók along with non-native primary stress on the second syllable of the first component. For the remaining two words $(j$ and $k$ ) we predict secondary stress on the first syllable for rhythmical reasons; non-native primary stress is on the third syllable in these words. 


\begin{tabular}{|c|c|c|c|c|c|c|c|c|}
\hline & WORD GROUP & EXAMPLES & TOKENS & $\begin{array}{l}\text { AVERAGE } \\
\text { VOT } \sigma 1\end{array}$ & $\begin{array}{l}\text { AVERAGE } \\
\text { VOT } \sigma 2\end{array}$ & $\begin{array}{l}\text { AVERAGE } \\
\text { VOT } 03\end{array}$ & $\begin{array}{l}\text { AVERAGE } \\
\text { VOT } \sigma 4\end{array}$ & $\begin{array}{l}\text { AVERAGE } \\
\text { VOT } 05\end{array}$ \\
\hline e. & $' \sigma \sigma \sigma_{i} \sigma \sigma$ & rómakøka & 17 & 51.5 & 42 & 42.5 & 40.0 & \\
\hline f. & $\sigma \sigma \# \sigma, \sigma \sigma$ & skrivimaskina & 5 & 47 & 34.1 & 39.5 & 39.2 & 41.0 \\
\hline g. & ' $\sigma \sigma \#(, \sigma \#, \sigma \sigma)$ & fútaskrivstova & 5 & 52.3 & 47.0 & 65.3 & 41.2 & 45 \\
\hline h. & $\begin{array}{l}' \sigma-\sigma \sigma \#, \sigma \sigma / \\
' \sigma \sigma \sigma \#, \sigma \sigma\end{array}$ & $\begin{array}{l}\text { samferðarmaður / } \\
\text { litingarpotur }\end{array}$ & 12 & 68 & 51.1 & 36.7 & 46.8 & 39.2 \\
\hline i. & $\sigma^{2} \sigma \sigma \ddot{\#}, \sigma$ & adressubók & 4 & 63.3 & 60 & 55 & 54.5 & \\
\hline j. & $\sigma \sigma \circ$ & telefon & 6 & 47 & 26.6 & 50.3 & & \\
\hline $\mathrm{k}$. & $\sigma \sigma^{\prime} \sigma \sigma$ & politistur & 2 & 55 & 28.9 & 65 & 40.5 & \\
\hline
\end{tabular}

Table 6: Voice onset time (VOT) of syllable onset $/ t /$ in msec; ta ta ta: 4 and 5 syllable words 


\begin{tabular}{|c|c|c|c|c|c|c|c|c|}
\hline & WORD GROUP & EXAMPLES & TOKENS & $\begin{array}{l}\text { AVERAGE } \\
\text { V } \sigma 1\end{array}$ & $\begin{array}{l}\text { AVERAGE } \\
V \sigma 2\end{array}$ & $\begin{array}{l}\text { AVERAGE } \\
V \sigma 3\end{array}$ & $\begin{array}{l}\text { AVERAGE } \\
\text { V } \sigma 4\end{array}$ & $\begin{array}{l}\text { AVERAGE } \\
\text { V } 05\end{array}$ \\
\hline e. & $' \sigma \sigma \#, \sigma \sigma$ & rómakøka & 17 & 167.5 & 150.4 & 154.5 & 116.6 & \\
\hline f. & ${ }^{\prime} \sigma \sigma \ddot{\#} \sigma, \sigma \sigma$ & skrivimaskina & 5 & 128.3 & 101.2 & 105.6 & 149.7 & 105 \\
\hline g. & $' \sigma \sigma \#(\sigma \#, \sigma \sigma)$ & fútaskrivstova & 5 & 166.9 & 147.7 & 129.5 & 110 & 96.2 \\
\hline h. & $\begin{array}{l}\sigma \sim \sigma \sigma \#, \sigma \sigma / \\
{ }^{2} \sigma \sigma \sigma \#, \sigma \sigma\end{array}$ & $\begin{array}{l}\text { samferðarmaður / } \\
\text { litingarpottur }\end{array}$ & 12 & 209.6 & 117.6 & 133.4 & 172 & 112 \\
\hline i. & $\sigma \cdot \sigma \sigma \#, \sigma$ & adressubók & 4 & 160.3 & 200 & 138.8 & 106.2 & \\
\hline j. &,$\sigma \sigma^{\prime} \sigma$ & telefon & 6 & 71.8 & 86.2 & 233.8 & & \\
\hline $\mathrm{k}$. &,$\sigma \sigma^{2} \sigma \sigma$ & politistur & 2 & 79.8 & 82.7 & 144.3 & 102.5 & \\
\hline
\end{tabular}

Table 7: Vowel duration (V) in msec; ta ta ta: 4 and 5 syllable words 


\begin{tabular}{|c|c|c|c|c|c|c|c|c|}
\hline & WORD GROUP & EXAMPLES & TOKENS & $\begin{array}{l}\text { AVERAGE } \\
\text { V } \sigma 1\end{array}$ & $\begin{array}{l}\text { AVERAGE } \\
V \approx 2\end{array}$ & $\begin{array}{l}\text { AVERAGE } \\
\text { V } \sigma 3\end{array}$ & $\begin{array}{l}\text { AVERAGE } \\
V \sigma 4\end{array}$ & $\begin{array}{l}\text { AVERAGE } \\
\text { V } \sigma 5\end{array}$ \\
\hline e. & $' \sigma \sigma \#, \sigma \sigma$ & rómakøka & 11 & 186 & 142 & 170 & 110 & \\
\hline f. & $\sigma \sigma \# \sigma, \sigma \sigma$ & skrivimaskina & 4 & 165.8 & 134.8 & 115.9 & 186.8 & 124.1 \\
\hline g. & $' \sigma \sigma \#\left(\sigma \#_{1} \sigma \sigma\right)$ & fütaskrivstova & 4 & 251.4 & 178.5 & 149.7 & 131.8 & 112.7 \\
\hline h. & $\begin{array}{l}' \sigma-\sigma \sigma \#, \sigma \sigma / \\
' \sigma \sigma \sigma \#, \sigma \sigma\end{array}$ & $\begin{array}{l}\text { samferðarmaður / } \\
\text { litingarpottur }\end{array}$ & 9 & 227.4 & 163.4 & 148.6 & 194 & 114.2 \\
\hline i. & $\sigma^{\prime} \sigma \sigma \#_{\mathrm{T}} \sigma$ & adressubók & 4 & 177 & 221.1 & 147 & 132 & \\
\hline j. & $\sigma \sigma \sigma^{\prime} \sigma$ & telefon & 5 & 93.9 & 83.7 & 224.4 & & \\
\hline $\mathrm{k}$. & $\sigma \sigma ' \sigma \sigma$ & politistur & 2 & 106.2 & 91.1 & 176.1 & 90.2 & \\
\hline
\end{tabular}

Table 8: Vowel duration (V) in msec; na na na: 4 and 5 syllable words 


\begin{tabular}{|c|c|c|c|c|c|c|c|c|}
\hline & WORD GROUP & EXAMPLES & TOKENS & $\begin{array}{l}\text { AVERAGE } \\
\text { C ol }\end{array}$ & $\begin{array}{l}\text { AVERAGE } \\
C \sigma 2\end{array}$ & $\begin{array}{l}\text { AVERAGE } \\
C \sigma \hat{3}\end{array}$ & $\begin{array}{l}\text { AVERAGE } \\
\mathrm{C} \sigma 4\end{array}$ & $\begin{array}{l}\text { AVERAGE } \\
C \sigma 5\end{array}$ \\
\hline e. & $\sigma \sigma H, \sigma \sigma$ & rómakøka & 13 & 64.3 & 92.4 & 93.0 & 83.3 & \\
\hline f. & ' $\sigma \sigma \# \sigma, \sigma \sigma$ & skrivimaskina & 4 & 66.3 & 73.6 & 59 & 72 & 77.3 \\
\hline g. & $\sigma \sigma \ddot{\#}(\sigma \stackrel{\#}{\#} \sigma \sigma)$ & fútaskrivstova & 4 & 60.81 & 83.4 & 71.6 & 97.6 & 108.1 \\
\hline h. & $\begin{array}{l}\sigma-\sigma \sigma \#, \sigma \sigma / \\
\sigma \sigma \sigma \#, \sigma \sigma\end{array}$ & $\begin{array}{l}\text { samferŏarmaður / } \\
\text { litingarpottur }\end{array}$ & 9 & 73 & 101.2 & 83 & 92.1 & 89.8 \\
\hline i. & $\sigma^{\prime} \sigma \sigma \dot{\prime}, \sigma$ & adressubók & 4 & 54.3 & 96.1 & 86.4 & 111.7 & \\
\hline j. & $\sigma \sigma^{\prime} \sigma$ & telefon & 5 & 78 & 57.5 & 79.2 & & \\
\hline $\mathrm{k}$. &,$\sigma \sigma^{\circ} \sigma \sigma$ & politistur & 2 & 37 & 54.3 & 69.2 & 75.5 & \\
\hline
\end{tabular}

Table 9: Consonant duration (C) in msec; na na na: 4 and 5 syllable words 


\section{VOT (Table 6)}

The average VOT' values for this second set of words clearly indicate that VOT is used as a cue for primary stress. Secondary stress, however, only correlates with VOT duration in four $(\mathrm{g}, \mathrm{h}, \mathrm{j}, \mathrm{k})$ out of the seven groups. In groups (e) and $(\mathrm{g})$, the morphological and rhythmical secondary stress prefer the third syllable. However, in groups (e) and (f) the main stressed syllable has a very high VOT value compared to all the other syllables where there is no differentiation in VOT. The words in group (g), on the other hand, do appear to mark the third syllable with some prominence since it has the longest average VOT of the word. It is even longer than the primary stressed syllable. In group (h), for which secondary stress is predicted to fall on the fourth syllable according to the compound rule, the VOT is indeed longer on this syllable than on the preceding and following ones, thus making it stand out from its surroundings in this way. In group (i) (adressubók), VOT duration does not reflect the predictions with regard to either primary or secondary stress positions. However, for the two remaining groups $(\mathrm{j})$ and $(\mathrm{k})$, VOT duration does reflect the predicted stress patterns such that the syllables carrying primary stress have the longest VOT averages and the second longest VOT values are on the word initial syllables, for which secondary stress is predicted following rhythmic alternation.

\section{Vowel duration (Tables 7 and 8)}

The average vowel duration in both the tatata and nanana tokens produced comparable results, clearly suggesting that vowel duration can be considered a correlate of both primary and secondary stress. In group (e), where the word stress rules (rhythm and morphology) predict primary stress on the initial syllable and secondary stress on the third syllable, this is reflected in the duration values. The vowel of the first syllable is longest, followed by the vowel of the third syllable, which in turn is longer than the second and fourth syllable (even if this effect is stronger for nanana than for tatata). In group ( $\mathrm{f}$ ), the second morphological component (maskina) demands non-native stress on its second syllable, and this is indeed reflected in the vowel duration, which is the longest for this syllable for both the tatata and nanana tokens. One possible explanation is vacillating stress patterns, another is that nonnative stress is marked more clearly. This latter explanation would be corroborated by the results for group (i) (adressubók), where the vowel of the second syllable, which bears nonnative primary stress, is clearly longer than all other vowels, without secondary stress being reflected in vowel duration. In group $(\mathrm{g})$, vowel duration behaves similar to VOT duration, such that it does reflect primary but not secondary stress, perhaps due to the conflict between alternating rhythm and morphological stress in the second component of the compound (similar to reydvinglas above). Group (h) follows very clearly the predicted pattern: primary stress (first syllable) is reflected in the longest vowel duration, followed by the second longest vowel duration in the fourth syllable, which bears secondary stress according to the compound rule. In groups $(j)$ and $(\mathrm{k})$, non-native primary stress is marked by longest vowel durations, while initial secondary stress is marked by second longest vowel duration in nananas but not tatatas. 


\section{Consonant duration (Table 9)}

As for the trisyllabic words, consonant duration of the nanana tokens does not reflect the predictions with respect to word stress. It only correlates with primary stress in the groups with non-native stress. Here (groups $\mathrm{i}-\mathrm{k}$ ) either the longest (for $\mathrm{j}$ ) or second longest consonants (for $\mathrm{i}$ and $\mathrm{k}$ ) are found in the onset of this syllable. Again, this reflects that non native stress is marked more clearly, even by this duration parameter, which does not otherwise seem to participate in the marking of stress.

\section{Pitch movement}

Finally, across all word groups, a systematic analysis with regard to pitch movement has yet to be done. However, upon first impression we do not find any results suggesting pitch as a phonetic cue to secondary stress. As can be seen in Figure 3 above, a local pitch peak can be found on the first na representing the syllable bearing primary stress. Secondary stress is predicted to occur on the fourth syllable (see (2)d in Table 1). However, while the fourth na in Figure 3 is clearly lengthened, no notable pitch movement other than continuation of the overall downward trend can be observed. This is despite the fact that stress is in a nonnative position here (second syllable of maskina), which is otherwise marked very clearly. This example is representative of the pattern which we seem to find for pitch movement across our data.

\subsection{Summary of results}

To summarise the results, we will return to the aims of this pilot study given at the end of Section 1 above and repeated here for convenience: (i) to ascertain the location of secondary stress in production and perception, (ii) to identify the most prominent phonetic parameters related to secondary stress in production and perception, and (iii) to compare secondary stress on lexical and functional morphemes.

First, the location of secondary stress in production and perception was tested in such a way that only those productions of tatatas and nananas were included in the analysis that were correctly identified by the other participant. The results include no surprises, i.e. the stress rules in (1) were confirmed for Faroese. Secondary stresses were phonetically implemented in the predicted positions or they were not implemented at all. In positions where there is a conflict between the rhythmical rule in (1)b and the morphological compound rule in (l)c, the compound rule wins (groups a and $h$ ). If there is no conflict, the secondary stress is not always implemented (groups $\mathrm{c}$ and e). Non-native stress is usually clearly marked, whether it is a primary stress or a secondary stress position (groups i-k and also group for vowel duration). Notice once again that the results reported on here are not for real words in real conversation and that the object of the game was to convey the words to the other participant to guess, hence the speech was possibly exaggerated at least for some tokens and certainly in repetitions. However, since secondary stress in Faroese has yet to be systematically studied, to reliably ascertain the position of secondary stress exaggeration was welcome.

Second, the most prominent phonetic parameters related to secondary stress are vowel duration (Tables 3, 4, 7 and 8) and VOT/aspiration (Tables 2 and 6). Pitch does not seem to 
play a role (cf. Figure 3). The duration of the initial consonant in nananas does not seem to be a reliable parameter in any way, thus we will not interpret it with regard to secondary stress (see the discussion of Tables 5 and 9 above). Remember in this context that only marginal aspiration is reported in the literature for internal onsets in Faroese. Looking at the values in the tables above and given that VOT corresponds to secondary stress positions in Faroese, aspiration may be marginal in internal onset positions, but it may also be strengthened and used to indicate word stress positions.

Third, looking at secondary stress associated with lexical and functional morphemes, no lengthening was found for inflectional suffixes in our Faroese data (e.g., -io in bikarid in group d). The assumption of alternating stress realised also on syllables corresponding to inflectional affixes could therefore not be corroborated. Future research will have to directly compare inflectional and derivational suffixes in an even more balanced design.

\section{Conclusion and outlook}

Regarding the location of secondary stress the Faroese results comply by and large with what we know from the literature. Faroese has alternating stress, but where morphology and rhythm conflict (e.g., morphological compounds with mono-syllabic first component) the compound rule wins. As for phonetic parameters, vowel duration has been identified as the most prominent cue to stress so far, together with VOT. Regarding the question of secondary stress associated with inflectional affixes, no lengthening effects were found for inflectional suffixes in our Faroese data. Moreover, although a systematic analysis of the na syllables has yet to be done, pitch movement does not seem to be a promising cue to secondary stress. However, to elicit pitch movement/pitch accents associated with syllables bearing secondary stress, the target words will be placed in an appropriate context in a future study. Overall, more data is needed to address the open questions that came up in the previous sections. In particular, in a follow-up we will include closed syllables in the word game, specifically with postvocalic preaspiration since we know that preaspiration in this position and syllable-closing consonants may be lengthened under stress in Icelandic (e.g., Ámason 2011, Árnason and Schäfer 2012) and possibly Faroese, although preaspiration behaves differently in the two languages (see Árnason 2011 for discussion). Furthermore, an even more balanced design and more tokens will put us in a position to follow up the differences between inflectional and derivational suffixes, and it will also allow us to systematically test the individual factors (e.g., stress position, alternating rhythm, position of morphological boundaries, nature of morphological boundaries (word formation vs. inflection; compounding vs. derivation)) for each phonetic parameter statistically. In addition, we will conduct an Icelandic word game for comparison. Ideally, words will be chosen which have the same morphological patterns as those used in Faroese, or the same lexical elements where possim ble. Also, the Icelandic target syllables will be as closely related to the Faroese ones as possible, i.e., Icelandic ta [thai] and $n a$ [nai] as open syllables, along with closed syllables with post-vocalic preaspiration (e.g., patt [phaht] or tipl [th $\mathrm{thpl}^{\mathrm{h}}$ ]). The comparison between the results of the experiments for the two languages will then put us in a position to answer 
the questions about differences in secondary stress positions in Icelandic and Faroese, as well as the relevant phonetic cues.

\section{Bibliography}

Árnason, K. (1985): Icelandic word stress and metrical phonology. Studia Linguistica 39: 93-129.

Ámason, K. (2011): The phonology of Icelandic and Faroese. Oxford: Oxford University Press.

Árnason, K. and M. Schäfer (2012): A stress test for segmenthood. Paper presented at the $11^{\text {th }}$ International Conference of Nordic and General Linguistics, 18--20 April 2012, University of Freiburg.

Barnes, M. P. and E. Weyhe (1994): Faroese. In: E.König and J. van der Auwera (eds.), The Germanic languages. London/New York: Routledge, 190-218.

Boersma, P. and D. Weenink (2012): Praat: doing phonetics by computer [Computer program]. Version 5.3.04. http://www.praat.org/

Dehé, N. (2008): To delete or not to delete: The contexts of Icelandic final vowel deletion. Lingua 118: 732-753.

Dehé, N. (2009): An intonational grammar for Icelandic. Nordic Journal of Linguistics 32: $5-34$.

Gussmann, E. (1985): The morphology of a phonological rule: Icelandic vowel length. In: E. Gussmann (ed.), Phono-morphology: Studies in the interaction of phonology and morphology. Lublin; RW KUL, 75-94.

Haugen, E. (1958): The phonemics of Modern Icelandic. Language 34: 55-88.

Hayes, B. (1995): Metrical stress theory: Principles and case studies. Chicago: The University of Chicago Press.

Kleber, F. and N. Klipphahn (2006): An acoustic investigation of secondary stress in German. Arbeitsberichte des Instituts für Phonetik und digitale Sprachverarbeitung der Universität Kiel (AIPUK) 37: 1-18.

Lockwood, H. (1977): An introduction to Modern Faroese. Tórshavn: Føroya Skúlabókagrumnur.

Plag, I., G. Kunter and M. Schramm (2011): Acoustic correlates of primary and secondary stress in North American English. Journal of Phonetics 39: 362-374.

Prieto, P. and J. van Santen (1996): Secondary stress in Spanish: some experimental evidence. In: C. Parodi, C. Quicoli, M. Saltarelli and M.L. Zubizaretta (eds.), Aspects of Romance linguistics. Washington, DC: Georgetown University Press, 337-356.

Thráinsson, H. and K. Árnason (1992): Phonological variation in 20 th century lcelandic. ĺslenskt mál 14: 89-128.

Thráinsson, H., H. P. Peterson, J. Jacobsen and Z. S. Hansen (eds.) (2004): Faroese: An overview and reference grammar. Tórshavn: Føroya Fróðskaparfelag.

Zonneveld, W., M. Trommelen, M. Jessen, C. Rice, G. Bruce and K. Árnason (1999): Wordstress in West-Germanic and North-Germanic languages. In: H. van der Hulst (ed.), Eurotyp 4: Word Prosodic Systems in the Languages of Europe. Berlin/New York: de Gruyter, 477-603. 
Holden Härtl (Ed.)

\section{Interfaces \\ of Morphology}

A Festschrift for Susan Olsen

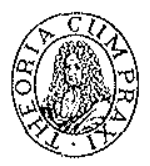

Akademie Verlag 
Bibliografische Information der Deutschen Nationalbibliothek

Die Deutsche Nationalbibliothek verzeichnet diese Publikation in der Deutschen Nationalbibliografie; detaillierte bibliografische Daten sind im Internet über http://dnb.d"nb.de abrufbar.

(c) Akademie Verlag GmbH, Berlin 2013

Ein Wissenschaftsverlag der Oldenbourg Gruppe

www.akademie-verlag.de

Das Werk einschließlich aller Abbildungen ist urheberrechtlich geschützt. Jede Verwertung außerhalb der Grenzen des Urheberrechtsgesetzes ist ohne Zustimmung des Verlages unzulässig und strafbar. Das gilt in sbesondere für Vervielfältigungen, Übersetzungen, Mikroverfilmungen und die Einspeicherung und Bearbeitung in elektronischen Systemen.

Umschlagentwurf: hauser lacour

Druck: Concept Medienhaus, Berlin

Bindung: Buchbinderei Klotz, Jettingen-Scheppach

Dieses Papier ist alterungsbeständig nach DIN/ISO 9706.

ISBN $\quad 978-3-05-006056-9$

elSBN $\quad 978-3-05-006379-9$ 